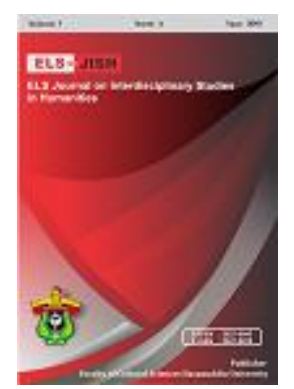

ELS-JISH

ELS Journal on Interdisciplinary Studies on Humanities

Volume 2 Issue 2, 2019

ISSN (print) : 2621-0843

ISSN (online) : 2621-0835

Homepage : http://journal.unhas.ac.id/index.php/jish

\title{
Character Building with Literature: Linguistic Creativity of Helen Keller in Writing Autobiography (The Story of My Life)
}

\author{
Juliastuti $^{1}$, Burhanuddin Arafah², Mustafa Makka3 \\ 1julie.smart25@yahoo.com
}

\begin{abstract}
The rapid development of online-social media has now provided greater convenience for transactions and interaction. It also greatly affects the mindset and behavior of user communication. Any information that is both positive and negative can easily be accessed by the public. And in admit or not, slowly began to change the pattern of life and thought patterns of people, especially bad language or hate speech with all the images that characterize them. The study of literature encourages empathy, tolerance for diversity, imagination and emotional intelligence which is the understanding of feelings, both of one's own and the others and literature as a medium in increasing the higher order thinking skill. The research is qualitative and descriptive in nature. The feminist paradigm of thought, a key framework among the poststructuralist paradigms and cognitive language are used as the conceptual framework for the execution of the research to reveal the creativity of Helen Keller. The method is qualitative descriptive. Helen Keller who after her illness, her infancy and early childhood were a succession of days of frustration become wild, unruly child" who kicked, scratched and screamed but literary works shaped her language and character into polite, creative, and empathy woman.
\end{abstract}

Keywords: Character building, linguistic creativity, literature.

How to cite: Juliastuti, et al. (2019). Character Building with Literature: Linguistic Creativity of Helen Keller in Writing Autobiography (The Story of My Life). ELS Journal on Interdisciplinary Studies in Humanities, 2 (2), 302-312.

\section{Introduction}

Digital technology that penetrates can be seen with the emergence of the internet community. Following the needs to follow accelerated technological advances, some people may feel tired following the latest new devices. But this is not for the younger generation. Everything in our teenage lives is somehow touched by technology, and they seem to understand very well how technology enables and influences our business and our lives. They not only follow technology, they eat it, they drive it, and they fight for it.

\footnotetext{
1, Instiut Agama Islam Negeri Palu, Indonesia

${ }^{2,3}$ Hasanuddin University, Indonesia
} 
These changes also have a profound impact on the transformation of existing values in society. Currently, in Indonesia we can see so much influence of technological progress towards cultural values in the embrace of society, both urban and rural (modernization). Technological advances such as television, telephones and mobile phones even the internet not only hit the city, but also has been enjoyed by people in villages.

As a result, any information that is both positive and negative can easily be accessed by the public. And in admit or not, slowly began to change the pattern of life and thought patterns of people, especially bad language or hate speech with all the images that characterize them.

The speed of this transformation in digital era follows the market needs in replacing ideas, products or soft wear and is heavily dependent on the role that young people play: they are a generation of disruptive era and they are the victim of the 'disruptive characters'.

Government regulations in the field of education in Indonesia have a vision and mission with the aim of national education to shape human education with life skills and good character formation. Character education values must be involved in designing and compiling material used in classroom learning activities. Character education issues about their effectiveness in class are partly due to the lack of practical evidence linking character education with positive emotional development in the academic field, social interaction, and emotional and cognitive improvement.

Consequently, the established communication in social media digitally has shaped students' mind sets and academic communication behaviors. In addition, it has affected the stabilization of academic communication in developing communication civilization among academicians; lecturers, students, staffs, and other academic members in higher education.

This is because the elements that support the outer life like competition, status, and achievement are not sufficient as meeting the needs for the inner life of children. They tend to promote the outer side of the person, with little contribution in the formation for the inner self.

This is evident with the last generation of children who have been educated in the media environment that affects them for the most part. Very often, children are left in front of the computer, for homework or just to relax, while in school educators can use a variety of teaching strategies and resources, some of them are also connected for technological development.

In this event, Rahman (2017), stated that literature is growing rapidly in line with technological development as part of human life. Literature as 'imaginative' writing and it uses language in peculiar ways it conformed to certain standards of 'polite letters' (Eagleton, T: 2003). Literature plays an important role in the personal children development because the reader is emotionally attached to the story and this has a positive effect not only on the person growth but also on the whole learning process (Regan, K., \& Page, P.2008). The study of literature also encourages empathy, tolerance for diversity, imagination and emotional intelligence which is the understanding of feelings, both of one's own and the others. 
Literature also as a medium in increasing the higher order thinking skill has been approved by Azmi (2013) He stated that in reading literary texts, readers become familiar with many different language forms, communicative functions and meanings, because they have to prepare with language proposed for native speakers. (Hişmanoğlu, M. 2005).

Viorela Stan in her research said that the teaching of literature in primary school with appropriate pedagogic methods and means not only develops linguistic abilities but also offers behavioural models which will contribute the children's personal fulfillment. From this point of view, the Romanian curriculum includes appropriate texts which can be used to these purposes. The literatures are selected based on class experience and can be varied according to the class level. (STAN, R.V: 2014)

As character education concepts are taught within the context of literature, students realize traits such as respect, honesty, courage, and kindness are real and interesting aspects of the world around them. Writers of trade books have much flexibility in their writing styles and can bring to the pages of their books richness of background, originality of style, and creativity, (Almerico, G. M. 2014).

Literary works can form characters can be found in Helen's Keller autobiography. Helen was blind and deaf when he was 18 months old. After Helen's illness, her infancy and early childhood were a succession of days of frustration, manifest by outbursts of anger and fractious behavior. "A wild, unruly child" who kicked, scratched and screamed was how she afterward described herself.

Helen is a worldwide speaker and writer and to this day she is remembered as an advocate for disabled people among many others. She and George Kessler founded the Helen Keller Institute (HKI) organization in 1915 dedicated to research in vision, health and nutrition. She also helped establish the American Civil Liberties Union (ACLU) in 1920. This extraordinary woman met every US President from Grover to Johnson and befriended many famous figures, including Alexander Graham Bell and Charlie Chaplin.

Helen Keller relates her impressions of life's beauty and promise, perceived through the sensations of touch, smell, and vibration, together with the workings of a powerful imagination. She wrote the story of her life in title 'The Story of My Life' begin struggling with her own feeling. It is shown in her first sentence of her book: It is with a kind of fear that I begin to write the history of my life. I have, as it were, a superstitious hesitation in lifting the veil that clings about my childhood like a golden mist. (Keller, Helen. 1903)

\section{Linguistic Creativity in the form of feminist stylistic and cognitive language.}

Chomsky said that "the 'creative' aspect of language use" as something which, he says manifests itself in the language user's ability to produce and understand "an indefinite number of expressions which are new to" his "experience", and to do so "on an appropriate occasion, despite their novelty and independently of detectable stimulus configurations" (Chomsky, N. 2007: 28)

Naturally, people who are deaf and/or blind can have trouble in communicating. They may not understand the concept of language because they have not been exposed to it. It means that communication and learning can be significant challenges for children with deafness and/or blindness. 
The culture provides the background for all the situations that we have to experience in order to be able to form a cognitive model. Background knowledge, in this case, necessarily involves gender assumptions, stereotypes, and ideologies that are present in society. This contains presuppositions about the capacity and the roles that a woman should play in society.

Cognitive models are of course not universal, but depend on the culture in which a person grows up and lives. The culture provides the background for all the situations that we have to experience in order to be able to form a cognitive model. Ungerer \& Schmid divide cultural models expert models which are based on hard scientific facts and the rules of logic, these types of assumptions would have no place. Naive cultural models, on the other hand, are based on informal observations, traditional beliefs, and even superstitions, and have therefore also been called 'folk models'. (Black, M: 1962)

In tracing the development from the traditional to a cognitive conception of metaphor, as now arrived at a crucial point already recognized by Black in a precognitive context, metaphors act as 'cognitive instruments'. In line with this, Suherman (2018) noted that, Metaphor grow with human experience which reflects a very meaningful idea about something which needs more cognitive thinking to interpret the actual meaning. This means that metaphors are not just a stylistically attractive way of expressing ideas by means of language, but a way of thinking about things.

In other words, when we use the following English phrases we establish links between two concepts that do not seem to belong together by their very nature:

- You're wasting my time.

- Can you give me a few minutes

- How do you spend your time?

- We are running out of time.

- Is that worth your while?

The first and the last journeys are reflected in language by metaphorical expressions such as the baby is on the way, the baby has arrived, we bring babies into the world, and he is still with us, they brought him back, he is gone, he has departed, he has passed away.

In acquiring her language Helen used her sense and smell, Bean \& Widger said about the power of those two human body tools that some of the most significant words relating to the human mind are borrowed from the sense of smell and the conspicuous place which its sensations occupy in the poetical language of all nations shows how easily and naturally they ally themselves with the refined operations of the fancy and the moral emotions of the heart. Helen certainly derives great pleasure from the exercise of these senses. (Bean \& Widger. 2013, 187)

Cognitive neuroscience pertains to the innate nature of language development and the underlying factors that determine this faculty. The explored of the neural correlates associated with language processing in a unique individual who is early blind, congenitally deaf, and possesses a high level of language function. In a 
normally sighted and hearing interpreter, identifying words through ASL was associated with left-lateralized activation of inferior frontal language areas. (Obretinova, et.al. 2009)

Helen is a deaf blind feminist writer having an elegant and peculiar 'polite' writing style. Her feminist attitude has been realized in her works and manifested through special and polite linguistic expressions. So, her works are the result of a beautiful blend of feminist tendencies and style excellence. Her works have gained widespread recognition and popularity.

The question of gender in literary texts has been approached by linguists in two different ways. The first involves a comparison of the fiction created by male and female authors and is typified by the search for "the femalesentence" or a specifically female style of writing. The second involves a study of the uses to which the linguistic gender system of different languages has been put in literary works. (Livia, A: 2003)

\section{Methodology}

This study is using a biographical research where the data collects all from the literature. This research uses narrative research as an approach. Biographical research on identity emphasizes a holistic-form analysis, on action modes emphasizes content analysis and it is mostly concerned with specific issues. Produce rich descriptions (of persons), structural types (action logics or how persons and structures are interlinked). The focus of this work is mainly on the language and symbolic level of identity-formation.

Narrative research is mostly in a lot of work on biography and autobiographical self-representation. But the focus of this work is mainly on the language and symbolic level of identity-formation.

\section{Source of Data}

The source approaches using a broad range of material from the autobiographical writing and the supporting data are collected from the literature sources of Helen Keller and the grounded theory sources.

\subsection{Method of Collecting Data}

The method of collecting data is determined as the most significant stage in completing this research. The researcher uses library research method in collecting the various sources related to the ground theories. The researcher collects the data through the autobiographies of Helen Keller.

The research focuses on the structure of the text, the semantics used and the sense/symbols transported by narratives, this includes questions of identity-formation and the link between discourses and identities. The steps of collecting data are:

1. Data Reduction: First, the mass of data has to be organized and somehow meaningfully reduced or reconfigured this first of three elements of qualitative data analysis as data reduction. Data reduction refers to the process of selecting, focusing, simplifying, abstracting, and transforming the data that appear in written up field notes or transcriptions. Not only do the data need to be condensed for the sake of manageability, they also have to be transformed so they can be made intelligible in terms of the issues being addressed. 
a. Selecting: This necessitates selective winnowing/sifting which refers to removing data from a group so that only the best ones which are relevant for answering particular research questions are left. The researcher uses the principle of selectivity to determine which data are to be singled out for description.

b. Focusing: The process of data reduction starts with a focus on distilling what the different respondents report about the activity, practice or phenomenon under study to share knowledge.

c. Simplifying: Data reduction often forces choices about which aspects of the accumulated data should be emphasised, reduced or set aside completely for the purposes of the topic at hand.

d. Abstracting: The data simplified should ensure that the richness of the data is not unfairly and unnecessarily diluted.

e. Transforming: The data are also transformed so that they can be made intelligible in terms of the issues being addressed

2. Data Display: Organizing groups of information, understanding what happens, further analysis/ action on the understanding. A display can be an extended piece of text or a diagram, chart or matrix that provides a new way of arranging and thinking about the more textually embedded data. Data displays, permits the researcher to extrapolate from the data enough to begin to identify systematic patterns and interrelationships. At the display stage, additional, higher order categories or themes may emerge from the data that go beyond those first discovered during the initial process of data reduction. Data display can be extremely helpful in identifying whether a system is working effectively and how to change it. The researcher:

a. Use data from two autobiographies and make a table of findings and enter them into an analysis chart

b. Prepare an analysis flow chart of 'my life story' and 'the world that I live in' as data sources

c. Enter the data found in the analysis chart of the theory used namely feminist stylistic, cognitive language and intertextuality.

3. Conclusion Drawing and Verification: Conclusion drawing requires a researcher to begin to decide what things mean. The researcher does this by noting regularities, patterns (differences/similarities), explanations, possible configurations, causal flows, and propositions. This process involves stepping back to consider what the analysed data mean and to assess their implications for the questions at hand. Verification, integrally linked to conclusion drawing, entails revisiting the data as many times as necessary to cross-check or verifies these emergent conclusions.

\section{Discussion}

In this present study, the autobiography (The Story of My Life) is thoroughly examined by isolating passages that illustrate the distinctive features that will help foreground linguistic creativity characteristics in the texts. These passages are classified into the different levels of analysis: word, phrase/sentence and discourse. 
Dominant features are then summarized in order to show the differences in the representations of the features. After showing, through a detailed analysis of the word, phrase/sentence, and discourse, features of the two autobiographies, the research proceeds to show some observations about the writing style/practice of Helen Keller.

In analyzing data, the narrative method used to describe the findings that emerge in this research. This research uses a descriptive analyzing to describe all the data that found and answered the problems that are mentioned.

Linguistic Creativity in Helen Keller's The Story of My Life (Keller, Helen. 1902)

Women, generally, use more adjectives in their conversation and writings. Excessive use of adjectives is a feminist characteristic. Helen Keller uses adjectives in her, "The Story of My Life" beyond normal rate. In the following table adjectives are given which Helen used in her said autobiography:

\begin{tabular}{|c|c|c|}
\hline superstitious & difficult & Earliest \\
\hline Vital & Great & tedious \\
\hline possession & charming & vivid \\
\hline celebrated & Large & finally \\
\hline completely & little & favorite \\
\hline Feel & stiff & comfort \\
\hline suddenly & beautiful & rare \\
\hline Long & satisfying & earthy \\
\hline simple & like & usual \\
\hline Lost & brief & rich \\
\hline delighted & dry & eager \\
\hline Fancy & alike & vividly \\
\hline interesting & important & little \\
\hline Loving & indulgent & devoted \\
\hline younger & small & such \\
\hline surrounding & emphatic & old \\
\hline Hot & $\mathrm{cool}$ & happily \\
\hline sweet & fragile & loveliest \\
\hline Early & soft & beginning \\
\hline Smooth & emphatic & last \\
\hline funny & wonderful & subtle \\
\hline Acute & Good & Loving \\
\hline Round & small & different \\
\hline
\end{tabular}




\begin{tabular}{lll}
\hline naughty & Little & coloured \\
\hline indifferent & Own & Well \\
\hline III & greatest & delicious \\
\hline Lazy & golden & blind \\
\hline intense & dull & inattentive \\
\hline special & hot & blazing \\
\hline Cold & eager & Pleased \\
\hline Understand & Long & enormous \\
\hline Tame & feel & Great \\
\hline Old & strong & Big \\
\hline Pleasant & emphatic & active \\
\hline Busy & disappointed & Enough \\
\hline contemptuous & clear & Distinct \\
\hline terrified & detached & earliest \\
\hline
\end{tabular}

It is observed that the writer is using those adjective words associated specifically with a feminist characteristic.

Rising intonation on declaratives characterize women's speech. In the autobiographies, we can note rising intonation as follow:

- Have you ever been at sea in a dense fog, when it seemed as if a tangible white darkness shut you in, and the great ship, tense and anxious, groped her way toward the shore with plummet and sounding-line, and you waited with beating heart for something to happen?

- $\quad$ "Is this not love?" I asked, pointing in the direction from which the heat came.

- How my childish imagination glowed with the splendour of their enterprise!

- No deaf child who has earnestly tried to speak the words which he has never heard--to come out of the prison of silence, where no tone of love, no song of bird, no strain of music ever pierces the stillness--can forget the thrill of surprise, the joy of discovery which came over him when he uttered his first word.

- But where is it now?

- Have I not the same right to use these words in describing what I feel as you have in describing what you see?

- How perfectly the definition fits my case in both senses of the word "apprehend" Women use intensifiers in their speech and there are a bundle of intensifiers used in the autobiographies: 
- They used to hang in long festoons from our porch, filling the whole air with their fragrance, untainted by any earthy smell; and in the early morning, washed in the dew, they felt so soft, so pure, I could not help wondering if they did not resemble the asphodels of God's garden.

- This made me so angry at times that I kicked and screamed until I was exhausted.

- I felt so cold

- When we were fortunate enough to find a nest I never allowed her to carry the eggs home, making her understand by emphatic signs that she might fall and break them.

- Curiously enough, the absence of eyes struck me more than all the other defects put together.

- I could never stay long enough on the shore.

- I felt absolutely alone, cut off from my friends and the firm earth

- He was unusually tender and kind to me, and for a brief space the shadow lifted.

The words in bold above are some intensifiers which make a speech linguistically peculiar and polite for women.

Helen expresses her thought about how books opened her knowledge. Knowing that books bring light into her dark world, she illustrates into poetic sentence 'knowledge floods the soul unseen with a soundless wave of deepening thought'. Some words like 'floods', 'unseen', 'soundless', 'deepening', mean knowledge surrounding her thought that only she can understand its role in her life.

- Such knowledge floods the soul unseen with a soundless tidal wave of deepening thought.

- Great poetry, whether written in Greek or in English, needs no other interpreter than a responsive heart.

- Sometimes a new word revived an image that some earlier experience had engraved on my brain.

- Everything Miss Sullivan taught me she illustrated by a beautiful story or a poem

She said 'needs no other interpreter than a responsive hearth', and her hearth fills with her memories of the meaning of every word she read before. She redefined it with her experience in reading some books and keeping it in her subconscious mind.

Helen uses these beautiful, poignant metaphors to describe the way she derives happiness from the experiences of others, even when she feels isolated and alone because of her condition. Her favorite books mentioned mean a great deal to her because they can bring her joy through their descriptions of the world they see and hear, allowing her to experience for herself what her deafness and blindness will 
not give her. This is what helps her get through debilitating feelings of loneliness and silence.

Helen expresses her emotion about the writer of her favourite book from her previous reading with some words like 'beautiful mouth, firm, true and tender'. She describes the mouth while she touched the medallion of 'Homer' and in fact brought her back to the work of 'homer' itself (Illiad).

- I think that was all; but I read them over and over, until the words were so worn and pressed I could scarcely make them out.

- Then she told me that she had a beautiful story about a little boy which she was sure I should like better than "The Scarlet Letter." The name of the story was "Little Lord Fauntleroy," and she promised to read it to me the following summer.

- I cannot remember what they all were, or in what order I read them; but I know that among them were "Greek Heroes," La Fontaine's "Fables," Hawthorne's "Wonder Book," "Bible Stories," Lamb's "Tales from Shakespeare," "A Child's History of England" by Dickens, "The Arabian Nights," "The Swiss Family Robinson," "The Pilgrim's Progress," "Robinson Crusoe," "Little Women," and "Heidi," a beautiful little story which I afterward read in German.

- Indeed, books have meant so much more in my education than in that of others, that I shall go back to the time when I began to read.

- One reading was sufficient to stamp every detail of the story upon my memory forever.

- I have since read Shakespeare's plays many times and know parts of them by heart, but I cannot tell which of them I like best.

- How well I know each line in that majestic brow--tracks of life and bitter evidences of struggle and sorrow; those sightless eyes seeking, even in the cold plaster, for the light and the blue skies of his beloved Hellas, but seeking in vain; that beautiful mouth, firm and true and tender.

Helen has found in her reading that some countries like Russian and French are very sensitive to the odors and it helps her illustrating her odor and describes it that the sense of smell is the esthetic sense which gives her a vivid conception of her surroundings. She said that Shakespeare is full of references to the olfactory sense, in Hamlet, Macbeth, Romeo and Juliet, Twelve Night, like she said that 'one reading was sufficient to stamp every detail of the story in my memory forever' and she also says 'I have read Shakespeare's plays many times and know parts of them by heart'. In sum she said that literature is her utopia.

Helen admitted that she likes to read Shakespeare's work over and over again to be able to remember part of the dramas. She reread the stories according to her heart's desire, so that literary work is Utopia (An imagined place or state of things in which everything is perfect) to her. By using literary works as a medium for the world of language, then Helen reuses the words of the works in her writing but with widespread meaning. 
To see the world, or how to see the world that Keller and we share, is to have ideas and imaginations, and to be used in language, in vocabulary and syntactic structures, that go together and connect the sensory available on the original path. Adjectives, male and female characterized with gender, and some intensifiers found as feministic style in Helen Keller's sentence structures that characterised as polite text.

\section{Conclusion}

Helen achievements in language acquisition as deft blind woman are trying to read the other person's lips fluently with her fingers, and, with great difficulty, to speaking subtle English but vague, in German, and, more clearly in French, and several other languages are.

Keller effectively advises, to have emotions, deliberate perceptions, personality, and consciousness. Consciousness and personhood are not just the cognitive command of language, but also the having of emotions. Keller has much to teach us.

\section{References}

Almerico, G. M. (2014). Building Character through Literacy with Children's Literature. Research in Higher Education Journal, 26.

Azmi, M. N. B. L. (2013). Developing Soft Skills Using" Literature Circles". Malaysian Online Journal of Educational Sciences, 1(2), 8-16.

Black, M. (1962). Models and metaphors: Studies in language and philosophy.

Chomsky, Noam. (2007). On Language: Chomsky's classic Works Language and Responsibilty and Reflections on Language. The New Press. New York: US

Eagleton, T. (2011). Literary theory: An introduction. John Wiley \& Sons

Hişmanoğlu, M. (2005). Teaching English through literature. Journal of Language and Linguistic studies, 1(1).

Keller, Helen. (1902). The Story of My Life. C. Rainfield. New York. USA.

Livia, A. (2003). 'One man in two is a woman': Linguistic approaches to gender in literary texts. The handbook of language and gender, 142.

Obretenova, S., Halko, M. A., Plow, E. B., Pascual-Leone, A., \& Merabet, L. B. (2010). Neuroplasticity associated with tactile language communication in a deaf-blind subject. Frontiers in human neuroscience, 3, 60.

Regan, K., \& Page, P. (2008). " Character" Building: Using Literature to Connect with Youth. Reclaiming Children \& Youth, 16(4).

Rahman, F. (2017). Cyber Literature: A Reader-Writer Interactivity, in International Journal of Social Sciences \& Educational Studies, ISSN 2520-0968 (online). ISSN 2409-1294 (print). June 2017, Vol.3, No 4.

Stan, R. V. (2015). The importance of literature in primary school pupils' development and personal growth. Procedia-Social and Behavioral Sciences, 180, 454-459. 
Juliastuti. 2(2): 302-312

Suherman, L. A. (2018). The Analysis of Metaphorical Domain on English "Stab Verb" in Corpora. ELS Journal on Interdisciplinary Studies in Humanities, 1(1), 52-58. DOI: http://dx.doi.org/10.34050/els-jish.v1i1.4190

Ungerer, F., \& Schmid, H. J. (2013). An introduction to cognitive linguistics. Routledge 